\title{
RESISTÊNCIA DE PICÃO-PRETO ENCONTRADA EM LAVOURA DE SOJA NA METADE SUL DO RIO GRANDE DO SUL
}

Jesus Juares Oliveira Pinto ${ }^{1}$; Jocemar Francisco Zanatta ${ }^{2}$; Lisiane Camponogara Fontana ${ }^{2}$; José Alberto Noldin ${ }^{4}$; Leandro Galon ${ }^{2}$; Mariane D Ávila Rosenthal'; Rodrigo Neves ${ }^{5}$

${ }^{1}$ Eng $^{\circ}$. Agr ${ }^{\circ}$., Prof. DFs/FAEM/UFPel, Caixa Postal 354, CEP.: 96010-900, Pelotas/RS, email:jesuspinto@terra.com.br (autor para correspondência), ${ }^{2} \mathrm{Eng}^{\mathrm{o}}$. $\mathrm{Agr}^{\circ}$., Mestrando no curso de PPFs/FAEM/UFPel, ${ }^{3}$ Eng $^{\circ}$. Agr ${ }^{\circ}$., Pesquisador da Epagri/Estação Experimental de Itajaí, SC. ${ }^{4}$ Eng $^{\circ}$. Agr ${ }^{\circ}$., DFs/FAEM/UFPel. ${ }^{5}$ Eng $^{\circ}$. Agr ${ }^{\circ}$., Pesquisador Dow Agrosciences, SP.

RESUMO: A resistência de plantas daninhas a herbicidas é um fenômeno de ocorrência mundial e que se caracteriza pela capacidade de um biótipo em sobreviver a um tratamento herbicida que controla os demais indivíduos de outros biótipos, componentes dessa espécie. Este trabalho teve o objetivo de determinar, o nível de resistência de biótipos de Bidens subalternans a diferentes herbicidas. Foram selecionados para o teste os herbicidas bentazon, fomesafen, imazethapyr e chloransulam-metil, aplicados, em pós-emergência, quando as plantas de $B$. subalternans apresentavam quatro pares de folhas. Os tratamentos herbicidas foram utilizados em doses crescentes, obedecendo à escala logarítmica de 0,$0 ; 0,001 ; 0,01 ; 0,1 ; 1,0 ; 10$ e 100 vezes a dose recomendada para controle. Os dados obtidos para controle foram obtidos visualmente, com auxílio da escala percentual. As relações entre o $\mathrm{C}_{50}$ do biótipo resistente e o $\mathrm{C}_{50}$ do biótipo suscetível (R/S) foram de 0,$79 ; 1,87,53,69$ e 486,02 para os herbicidas bentazon, fomesafen, imazethapyr e chloransulam-metil, respectivamente. A resistência de plantas daninhas a herbicidas ocorre nas lavouras de soja do sul do RS e o biótipo R de B. subalternans apresentou elevado nível de resistência cruzada a herbicidas inibidores da ALS, dos grupos químicos das imidazolinonas e sulfonanilidas.

Palavras-chave: ALS, imidazolinonas, sulfonanilidas, chloransulam-metil, imazethapyr.

\section{RESISTANCE OF BEGGARTICKS (Bidens subalternans L.) IN FARMING OF SOY OF RIO GRANDE DO SUL}

\begin{abstract}
Weed herbicide resistance is a phenomenon defined as ability of a biotype survives to herbicide sprayed, at a recommended rate that control a susceptible population. This research had the objective of determine, the level of resistance the herbicides of the Bidens subalternans. The herbicides treatments they were with bentazon, fomesafen, imazethapyr e chloransulam-methyl. Sprayed in post-emergency, when B. subalternans reached stage four-leaf pairs. The herbicide rates sprayed was crescents in a logarithm scale of 0,$0 ; 0,001 ; 0,01 ; 0,1$; 1,$0 ; 10$ e 100 times of the control recommended rate. Through visual evolution and with aid of the percentile scale they were obtained the control data. The ratio between the $\mathrm{C}_{50}$ of the resistant biotype, and $\mathrm{C}_{50}$ of the susceptible biotype $(\mathrm{R} / \mathrm{S})$ were $0,79,1,87,53,69$ and 486,02 to the herbicides bentazon, fomesafen, imazethapyr and chloransulam-methyl, respectively. The weed herbicide resistance happen in Rio Grande do Sul soybean fields and the biotypes R of $B$. subalternans presented high level of cross-resistance the herbicides inhibitions of ALS, of the chemical groups of the imidazolinones and sulfonanilides.
\end{abstract}

Key words: ALS, imidazolinones, sulfonanilides, chloransulam-methyl, imazethapyr. 


\section{INTRODUÇÃO}

A ocorrência de plantas daninhas resistentes a herbicidas tem se constituído, um dos grandes problemas enfrentados pela comunidade agrícola. A ineficácia da ação dos herbicidas sobre biótipos resistentes vem diminuindo as alternativas para realizar o controle químico de espécies daninhas que tornaram-se resistentes. Christoffoleti et al. (2004) consideraram como principais conseqüências da resistência de plantas daninhas a herbicidas, a restrição ou inviabilização da utilização desses produtos, perdas de áreas de plantio, redução na produtividade, qualidade do produto agrícola, necessidade de reaplicação de herbicidas, mudanças no sistema de produção que, em alguns casos, estão requerendo doses cada vez maiores dos herbicidas. Dessas novas medidas, surgem como conseqüências: maiores riscos de impacto ambiental negativo, aumento nos custos de produção e conseqüente redução da competitividade na comercialização do produto final.

A resistência de plantas daninhas aos herbicidas dentro de uma determinada população, é a capacidade adquirida e herdável de alguns biótipos, da mesma espécie, de sobreviverem e se reproduzirem após a exposição à dose de um herbicida (Christoffoleti et al., 2004). Por sua vez, a pressão de seleção gerada pelos herbicidas, aumenta a freqüência dos biótipos resistentes (Rizzardi et al., 2002). A utilização de herbicidas com residual prolongado ou herbicidas sem ação residual, mas aplicados repetidamente, o uso de herbicidas com alto grau de eficiência no controle do biótipo suscetível e, a aplicação de doses elevadas proporcionam uma pressão de seleção muito grande, favorecendo o desenvolvimento do biótipo resistente (Christoffoleti et al., 1994; Vidal \& Fleck, 1997a).

Os herbicidas inibidores da ALS começaram a ser comercializados no início da década de 80 e os primeiros relatos de resistência no Brasil foram documentados por Christoffoleti et al. (1996), Ponchio et al. (1996) e Vidal \& Fleck (1997b), com as espécies Bidens pilosa e Euphorbia heterophylla. O rápido surgimento de biótipos resistentes deve-se ao fato destes herbicidas terem sido utilizados de forma intensiva e continua, mas também devido ao sítio de ação ser único. A mutação na enzima ALS responsável pela resistência é nuclear e, no mínimo parcialmente dominante, sendo transmitida tanto por semente quanto pelo pólen (Tranel \& Wright, 2002).

A ALS é a primeira enzima da rota de síntese dos aminoácidos de cadeia ramificada: valina, leucina e isoleucina, Kissmann (2004). A inibição da síntese dos aminoácidos leva a uma interrupção na divisão celular e paralisação do crescimento. Após a absorção, esses herbicidas são rapidamente translocados para a área de crescimento ativo, inibindo o desenvolvimento da planta, fato este que segundo Oliveira Jr. (2001) faz com que as plantas acabem morrendo, devido à incapacidade de produzir os aminoácidos essenciais para o seu crescimento.

O picão-preto é uma planta nativa da América do Sul, de ciclo anual, e infesta a maioria das áreas destinadas a culturas anuais, invadindo também culturas perenes. A infestação constitui-se de uma mistura das espécies Bidens pilosa e Bidens subalternans, cujo domínio da espécie, depende da região. Uma das culturas anuais mais afetadas pela concorrência do picãopreto é a da soja, cujo decréscimo de rendimento pode ficar em torno de $30 \%$, quando intensamente infestada (Kissmann \& Groth, 1999).

Sabe-se da existência de biótipos de picão-preto com resistência cruzada aos herbicidas inibidores da ALS dos grupos das sulfoniluréias e imidazolinonas, pois a espécie de $B$. subalternans apresentou elevado nível de resistência cruzada aos herbicidas chlorimuron-ethyl e imazethapyr (Gelmini, 2001; 2002).

A população de $B$. pilosa e B. subalternans estudada por Monquero et al. (2000) apresentou taxas de resistência (R/S) de 9,90 para os herbicidas chlorimuron-ethyl, 9,07 para nicosulfuron e 27,03 para imazethapyr, enquanto que Christoffoleti (2002) confirma a existência de biótipos de $B$. pilosa com níveis de resistência de 40,92; 173,84; 57,47 e 57,16; 
para os herbicidas chlorimuron-ethyl, nicosulfuron, metsulfuron-methyl e imazethapyr, respectivamente.

Este trabalho teve o objetivo de determinar o nível de resistência de biótipos resistente e suscetível de picão-preto a herbicidas.

\section{MATERIAL E MÉTODOS}

O experimento foi conduzido em condições de casa-de-vegetação localizada no campus da Universidade Federal de Pelotas (UFPel), no município de Capão do Leão-RS.

As sementes de picão-preto (B. subalternans L.) supostamente resistente aos herbicidas inibidores da ALS, foram provenientes de uma área localizada na região de Pelotas, no Estado do Rio Grande do Sul. As unidades experimentais foram representadas por potes plásticos com capacidade para $1,5 \mathrm{dm}^{3}$, preenchidos com solo proveniente de área agrícola. As sementes do biótipo suscetível foram coletadas na Região da Cascata, município de Pelotas-RS. Após a emergência fez-se o desbaste mantendo-se sete plantas por vaso, que apresentavam desenvolvimento e crescimento uniformes. A adubação foi realizada de acordo com a análise de solo, seguindo-se as recomendações para a cultura da soja. A irrigação foi diária, mantendo-se o solo com umidade suficiente para repor as perdas.

$\mathrm{O}$ delineamento experimental foi o de blocos inteiramente casualizados, em esquema fatorial 4 x 7, com quatro herbicidas e sete doses distribuídos em quatro repetições. Os herbicidas e as doses comerciais de referência utilizadas foram: bentazon (Basagran CS 600 $1,2 \mathrm{~L} \mathrm{ha}^{-1}+$ Assist 0,5\% v/v), fomesafen (Flex $-1 \mathrm{~L} \mathrm{ha}^{-1}+$ Energic 0,2\% v/v), imazethapyr (Pivot - $1 \mathrm{~L} \mathrm{ha}^{-1}$ ) e chloransulan-metil (Pacto - $40 \mathrm{~g} \mathrm{ha}^{-1}+$ Agral 0,2\% v/v).

Os tratamentos corresponderam a 0,$0 ; 0,001 ; 0,01 ; 0,1 ; 1,0 ; 10$ e 100 vezes a dose recomendada de cada herbicida para, em condições de campo, controlar a espécie $B$. Subalternans. Os herbicidas foram aplicados, em pós-emergência, quando as plantas daninhas apresentavam quatro pares de folhas verdadeiras. Para a aspersão do herbicida foi utilizado pulverizador costal pressurizado a $\mathrm{CO}_{2}$ comprimido, munido de um bico de jato plano, tipo leque, modelo XR 110.02, com pressão de trabalho de $250 \mathrm{kPa}$ e barra postada a $40 \mathrm{~cm}$ da superfície do alvo, proporcionando a aplicação de um volume de $120 \mathrm{~L} \mathrm{ha}^{-1}$ de calda herbicida. A irrigação das plantas aspergidas ocorreu somente no dia seguinte, tempo suficiente a absorção dos herbicidas.

A avaliação foi realizada 21 dias após a aplicação dos tratamentos (DAT), quando foram determinados os níveis de controle, avaliados visualmente, atribuindo-se valores de zero (0) até cem (100) por cento, indicando respectivamente ausência de controle e morte completa das plantas tratadas.

Os dados observados na avaliação visual de controle foram submetidos à análise de variância considerando-se, as doses como variáveis independentes e a resposta ao acréscimo de dose como variável dependente servindo de base para o teste de precisão no ajuste do modelo não-linear. Em seguida, os dados foram analisados utilizando o programa de ajuste "Curve expert 1.3". Cada conjunto foi caracterizado através da equação que melhor representou o comportamento da variável dependente dentro de cada biótipo em relação ao efeito dos tratamentos com herbicidas e suas respectivas doses. Curvas típicas de dose resposta têm formato sigmóide e a expressão matemáticaque relaciona a resposta $(\mathrm{y})$ e dose (x) é:

$$
\mathrm{y}=\left(\mathrm{a} b+\mathrm{c} \mathrm{x}^{\mathrm{d}}\right) /\left(\mathrm{b}+\mathrm{x}^{\mathrm{d}}\right)
$$

onde, ' $y$ ' representa o controle de $B$. subalternans, 'a' é a assíntota máxima, 'b' é o coeficiente de declividade, 'c' diferença entre o ponto máximo e mínimo da curva, 'd' é a declividade da curva e ' $x$ ' representa a dose do herbicida.

As equações de ajuste permitiram o cálculo da dose que proporcionou $50 \%$ de controle $\left(\mathrm{C}_{50}\right)$ em relação à testemunha. A partir desses valores foi determinado o grau de resistência, 
que indicou o número de vezes superiores à dose necessária do herbicida para controlar $50 \%$ dos indivíduos de uma população suscetível.

\section{RESULTADOS E DISCUSSÃO}

As curvas de dose-resposta, para os herbicidas estudados estão representadas na Figura 1. Nesta Figura pode-se observar que, independentemente dos herbicidas utilizados, estando inclusos também os de diferentes mecanismos de ação, aumentos progressivos na dose ocasionaram um aumento no controle, tanto para o biótipo $\mathrm{S}$ quanto para o biótipo $\mathrm{R}$. Resultados semelhantes foram observados por Christoffoleti (2002) com os herbicidas chlorimuron-ethyl, nicosulfuron, metsulfuron-methyl e imazethapyr para a espécie B. pilosa. Também, tendências similares foram observadas por Monquero et al. (2003) para o controle das espécies $B$. pilosa e Amaranthus quitensis com a utilização de chlorimuron-ethyl, nicosulfuron e imazethapyr.

Os herbicidas bentazon e fomesafen, proporcionaram $100 \%$ de controle das plantas, evidenciando que os dois biótipos testados são suscetíveis a estes produtos (Figura 1). Para o herbicida imazethapyr, observou-se que foi possível obter $100 \%$ de controle para o biótipo S, entretanto para o biótipo $\mathrm{R}$ só atingiu $100 \%$ de controle quando a planta daninha recebeu aspersão 100 vezes superior à dose recomendada. Isto sugere uma diferença no grau de suscetibilidade entre os biótipos para o herbicida imazethapyr. Comportamento semelhante foi observado por Christoffoleti (2003) ao avaliar a ação de imazethapyr em um biótipo resistente de $B$. pilosa.

Para o herbicida chloransulam-metil, obteve-se 97\% de controle para o biótipo suscetível a partir de $10 \%$ da dose comercial, enquanto para o biótipo resistente o nível máximo de controle atingido foi de $85 \%$ e, somente quando as plantas resistentes foram aspergidas com 100 vezes a dose comercial para o controle de B. subalternans (Figura 1).

A utilização dos herbicidas inibidores da fotossíntese e protox na dose recomendada exerceram um controle eficaz em ambos os biótipos (Figura 1). Estes resultados se assemelham àqueles observados por Gazziero (2003) que confirma serem os herbicidas destes grupos uma alternativa para o manejo do biótipo resistente de B. subalternans. Monquero et al. (2003) confirmam que os herbicidas lactofen, fomesafen e bentazon foram eficientes no controle de $B$. pilosa resistentes a inibidores da ALS.

Os valores dos parâmetros da equação de ajuste para o cálculo da $\mathrm{C}_{50}$ encontram-se na Tabela 1 e os valores da $C_{50}$ calculados a partir das equações de ajuste são apresentados na Tabela 2. Verificou-se que a $\mathrm{C}_{50}$ dos herbicidas testados para o biótipo suscetível ficou abaixo da dose recomenda (Tabela 2). Comportamento semelhante também foi observado para os herbicidas bentazon e fomesafen em relação ao biótipo resistente. Entretanto, para os herbicidas inibidores da ALS, imazethapyr e chloransulam-metil, a $\mathrm{C}_{50}$ foi superior à dose comercial atingindo 698,04 e 66,099 $\mathrm{g} \mathrm{ha}^{-1}$, respectivamente. Com base nestes resultados, constatou-se que para o biótipo R de B. Subalternans o nível de resistência foi de 53,69 e 486,02 vezes para imazethapyr e chloransulam-metil, respectivamente. Essa situação evidencia a ocorrência de resistência cruzada para o biótipo resistente de $B$. subalternans aos herbicidas inibidores da ALS chloransulam-metil e imazethapyr. 

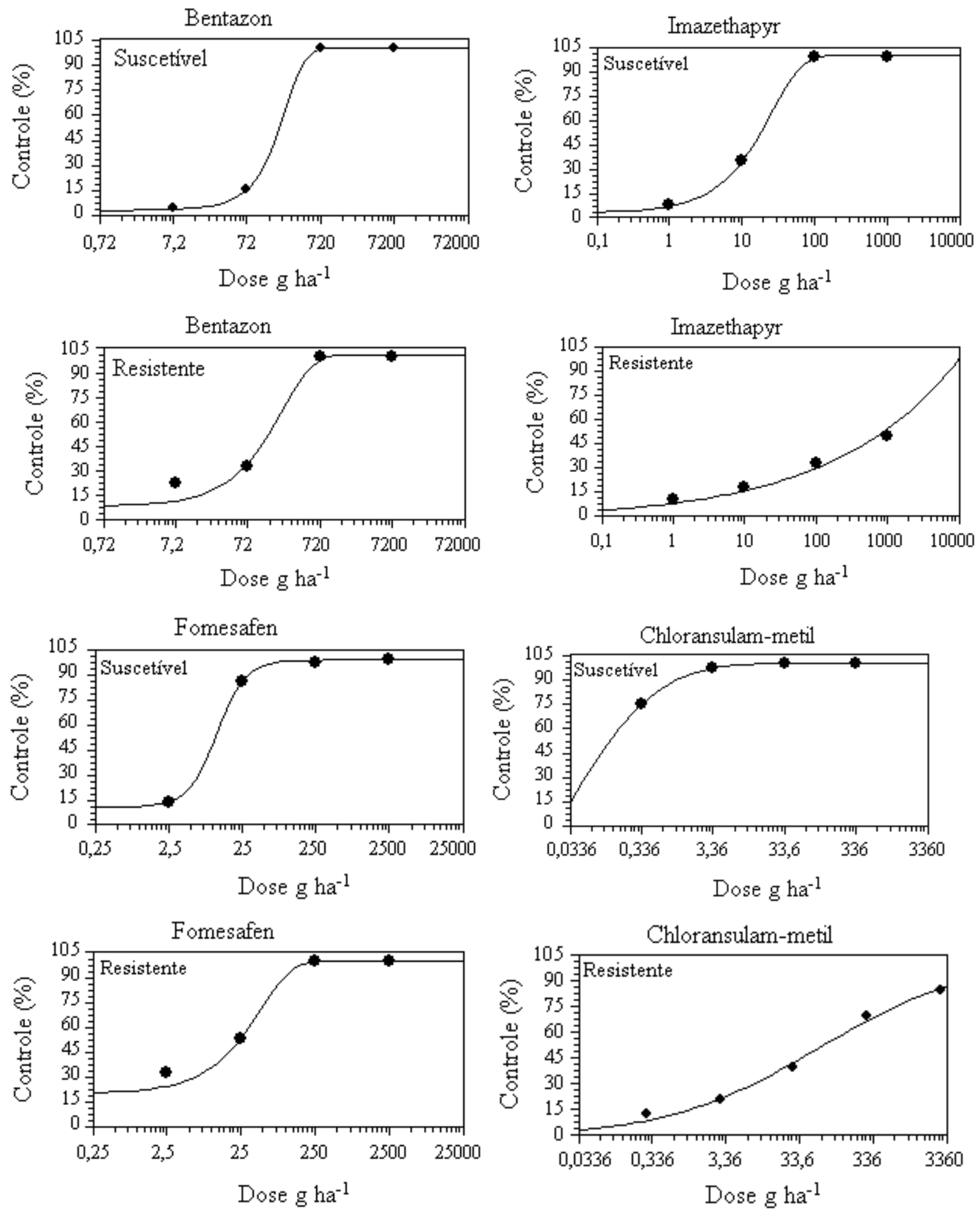

Figura 1. Curvas de dose-resposta dos herbicidas bentazon, fomesafen, imazethapyr e chloransulam-metil para biótipos R e S de Bidens subalternans.

Powles \& Howat (1990), Christoffoleti et al (1994), Christoffoleti (2002) e Monquero et al. (2003) também observaram que biótipos resistentes de Bidens pilosa podem apresentar resistência cruzada a inibidores da ALS tanto para sulfoniluréias quanto para imidazolinonas. A ocorrência da resistência pode estar relacionada a presença de genótipos que sobreviveram na comunidade original em níveis bastante baixos e foram sendo selecionados pelo uso repetido do 
mesmo herbicida ou de diferentes herbicidas com o mesmo modo de ação como foi considerado por Guttieri et al (1992) e Vidal \& Fleck (1997c).

A resistência de plantas daninhas continua relevante, uma vez que a cada ano agrícola, surgem biótipos resistentes. Os resultados encontrados apontam soluções para controlar populações de $B$. subalternans constituídas por biótipos resistentes inibidores da ALS.

Tabela 1. Parâmetros da equação de dose-resposta do biótipo S e R de B. subalternans, para a variável controle, com os herbicidas testados

\begin{tabular}{lccccc}
\hline \multirow{2}{*}{ Herbicidas } & \multicolumn{5}{c}{ Biótipo suscetível } \\
\cline { 2 - 6 } Bentazon & $\mathrm{a}$ & $\mathrm{b}$ & $\mathrm{c}$ & $\mathrm{d}$ & $\mathrm{R}^{2}$ \\
Imazethapyr & 3,9746 & 2207011 & 100,2394 & 2,9622 & 0,999 \\
Fomesafen & 5,4083 & 602,595 & 100,2492 & 2,4374 & 0,999 \\
Chloransulam-metil & 10,9473 & 212,9777 & 99,3676 & 2,2292 & 0,999 \\
\hline & 100,7588 & 0,1380 & - & - & 0,996 \\
\hline Herbicidas & $\mathrm{a}$ & $\mathrm{b}$ & $\mathrm{c}$ Biótipo resistente & $\mathrm{d}$ & $\mathrm{R}^{2}$ \\
\hline Bentazon & 11,2926 & 30916,283 & 100,6048 & 2,1559 & 0,987 \\
Imazethapyr & $-1,8043$ & 1003,92 & 10187,18 & 0,2498 & 0,995 \\
Fomesafen & 20,0048 & 45,2277 & 102,1633 & 1,1119 & 0,992 \\
Chloransulam-metil & $-1,5696$ & 22,1438 & 104,4720 & 0,4106 & 0,996 \\
\hline
\end{tabular}

Tabela 2. Valores de $\mathrm{C}_{50}{ }^{(1)}$ dos biótipos R e S de B. subalternans aos herbicidas testados

\begin{tabular}{lccc}
\hline Herbicidas & $\mathbf{R}$ & $\mathbf{S}$ & $\mathbf{R} / \mathbf{S}$ \\
\hline Bentazon & 107,46 & 134,51 & 0,79 \\
Imazethapyr & 698,04 & 13,26 & 53,69 \\
Fomesafen & 18,73 & 9,97 & 1,87 \\
Chloransulam-metil & 66,099 & 0,136 & 486,02 \\
\hline
\end{tabular}

${ }^{(1)} \mathrm{C}_{50}$ dose do herbicida em $\mathrm{g}$ ha ${ }^{-1}$ necessário para proporcionar $50 \%$ de controle da planta daninha. R/S- divisão do $\mathrm{C}_{50}$ do biótipo resistente pelo $\mathrm{C}_{50}$ do biótipo suscetível.

\section{BIBLIOGRAFIA CITADA}

CHRISTOFFOLETI, P.J.; VICTORIA FILHO, R.; DA SILVA, C.B. Resistência de plantas daninhas aos herbicidas. Planta Daninha, v.12, n.1, p.13-20, 1994.

CHRISTOFFOLETI, P.J. et al. Imidazolinone resistance Bidens pilosa biotypes in the Brazilian soybean areas. In: MEETING OF THE WEED SCIENCE SOCIETY OF AMERICA, $36^{\text {th }}$., 1996, Norfolk. Abstracts... Champaing: WSSA, 1996. p.10.

CHRISTOFFOLETI, P.J. Curvas de dose-resposta de biótipos resistente e suscetível de Bidens pilosa L. aos herbicidas inibidores da ALS. Scientia Agrícola, v.59, p.513-519, 2002.

CHRISTOFFOLETI, P.J. (Coord.); OVEJERO, R.F.L.; CARVALHO, J.C. Aspectos de resistência de plantas daninhas a herbicidas. 2.ed. Campinas: Associação Brasileira de Ação a Resistência de Plantas aos Herbicidas (HRACBR), 2004. 100p. 
GAZZIERO, D.L.P.; PRETE, C.E.C.; SUMIYA, M. Manejo de Bidens subalternans resistente aos herbicidas inibidores da acetolactato sintase. Planta Daninha, v.21, n.2, p.283-291, 2003.

GELMINI, G.A. Resistência de biótipos de Euphorbia heterophylla L., Bidens subalternans L., e Brachiaria plantaginea (L.) Hitchc. a herbicidas utilizados na cultura da soja (Glycine max (L.) Merril). 2001. 147f. Dissertação (Mestrado em Fitotecnia) - Escola Superior de Agricultura "Luiz de Queiroz", Piracicaba.

GELMINI, G.A. et al. Resistência de Bidens subalternans aos herbicidas inibidores da enzima acetolactato sintase utilizados na cultura da soja. Planta Daninha, v.20, n.2, p.319-325, 2002.

GUTIERRI, M.J. et al. DNA sequence variation in domain A of the acetolactate synthase genes of herbicide-resistant and susceptible weed biotypes, Weed Science, v.40, p.670-676, 1992.

KISSMANN, K.G.; GROTH, D. Plantas infestantes e nocivas. São Paulo: Basf Brasileira, 1999. t.2, 978p.

KISSMANN, K.G. Resistência de plantas daninhas a herbicidas. Disponível em: $<$ http://www.hrac-br.com.br/arquivos/texo resistencia herbicidas.doc $>$. Acesso em: 09 nov. 2004.

MONQUERO, P.A.; CHRISTOFFOLETI, P.J.; DIAS, C.T.S. Resistência de plantas daninhas aos herbicidas inibidores da ALS na cultura da soja (Glycine max). Planta Daninha, v.18, p.419-425, 2000.

MONQUERO, P.A. Biologia, manejo e caracterização bioquímica e genética de biótipos resistentes aos herbicidas inibidores da acetolactato sintase. Scientia Agrícola, v.60, n.3, p.495$503,2003$.

OLIVEIRA Jr., R.S. Mecanismos de ação de herbicidas. In: OLIVEIRA Jr., R.S.; CONSTANTIN, J. (Coord.). Plantas daninhas e seu manejo. Guaíba: Agropecuária, 2001. p.209-260.

PONCHIO, J.A.R. et al. ALS enzyme assay from Bidens pilosa biotypes of the Brazilian soybean areas to determine the sensitivy to imidazolinona and sulfonilurea herbicides. In: MEETING OF THE WEED SCIENCE SOCIETY OF AMERICA, 36 ${ }^{\text {th }}$, 1996, Norfolk. Abstracts... Champaing: WSSA, 1996. p.79.

PONCHIO, J.A.R. Resistência de Bidens pilosa L. aos herbicidas inibidores da enzima acetolactato sintase. 1997. 138f. Tese (Doutorado em Fitotecnia) - Escola Superior de Agricultura "Luiz de Queiroz", Piracicaba.

POWLES, S.B.; WOWAT, P.D. Herbicide-resistant weeds in Austrália. Weed Technology, v.4, p.178-185, 1990.

RIZZARDI, M.A. et al. Resistência de plantas aos herbicidas inibidores da acetolactato sintase. Planta Daninha, v.20, n.1, p.149-158, 2002.

TRANEL, P.J.; WRIGHT, T.R. Resistance of weeds to ALS-inhibiting herbicides: What have we learned? Weed Science, v.50, p.700-712, 2002. 
VIDAL, R.A.; FLECK, N.G. Herbicidas: mecanismos e ação e resistência de plantas. Porto Alegre: Palotti, 1997a, 165p.

VIDAL, R.A.; FLECK, N.G. Three weed species with confirmed resistance to herbicides in Brazil. In: MEETING OF THE WEED SCIENCE SOCIETY OF AMERICA, 37 ${ }^{\text {th }}$, 1997, Orlando. Abstracts... Champaing: WSSA, 1997b. p.100.

VIDAL, R.A.; FLECK, N.G. Análise de risco da ocorrência de biótipos de plantas daninhas resistentes aos herbicidas. Planta Daninha, v.15, p.152-161, 1997c. 